\title{
Electrically Heated Tube Investigation of Cooling Channel Geometry Effects
}

Michael L. Meyer

Lewis Research Center

Cleveland, Ohio

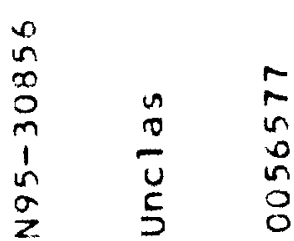

Prepared for the 31st Joint Propulsion Conference and Exhibit cosponsored by AIAA, ASME, SAE, and ASEE San Diego, California, July 10-12, 1995

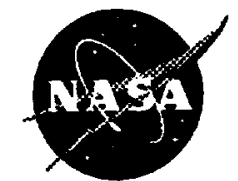

National Aeronautics and Space Administration 


\title{
Electrically Heated Tube Investigation of Cooling Channel Geometry Effects
}

\author{
Michael L. Meyer* \\ NASA Lewis Research Center \\ 21000 Brookpark Road \\ Cleveland, Ohio 44135
}

\begin{abstract}
The results of an experimental investigation on the combined effects of cooling channel aspect ratio and curvature for rocket engines are presented. Symmetrically heated tubes with average heat fluxes up to 1.7 $\mathrm{MW} / \mathrm{m}^{2}$ were used. The coolant was gaseous nitrogen at an inlet temperature of $280 \mathrm{~K}$ (500 $\left.{ }^{\circ} \mathrm{R}\right)$ and inlet pressures up to $1.0 \times 10^{7} \mathrm{~N} / \mathrm{m}^{2}(1500$ psia). Two different tube geometries were tested: a straight, circular cross-section tube, and an aspect-ratio 10 cross-section tube with a $45^{\circ}$ bend. The circular tube results are compared to classical models from the literature as validation of the system. The curvature effect data from the curved aspectratio 10 tube compare favorably to the empirical equations available in the literature for low aspect ratio tubes. This latter result suggests that thermal stratification of the coolant due to diminished curvature effect mixing may not be an issue for high aspect-ratio cooling channels.
\end{abstract}

\section{Introduction}

The cooling passages of regeneratively cooled rocket engines have traditionally been designed with low height-to-width dimensional aspect ratio. Recent experiments have suggested that improved thrust chamber liner cooling could be achieved by using high aspect ratio (AR>4) passages. 1 But, because only limited data were obtained in these experiments, further parametric studies were required to fully understand the potential benefits.

The primary issue that remained from the previous work revolved around the curvature heat transfer enhancement. This enhancement provides additional cooling in the thrust chamber throat region, where the chamber liner receives the highest hot-gas side heat loads. The enhancement occurs because, as the coolant curves through the throat, a pair of secondary flow vortices develop which not only mix the coolant but also force cooler fluid to the hot wall. Since the previous experiments were performed with straight passages, the curvature effect was not investigated. Concerns have been raised that the tall thin passages might break down the vortex pair and reduce the curvature enhancement. A numerical investigation predicted that, if the secondary flow mixing were reduced, the coolant would become thermally stratified, and the hot-gas wall temperatures would be significantly higher. ${ }^{2}$

The issue was resolved in part by a flow visualization study of the secondary flow development in a curving high aspect ratio (AR $=5$ ) channel. 3 The study showed qualitatively that the secondary vortex pair developed. But because the study was limited to low turbulent Reynold's numbers and the strength of the secondary flow was not quantified, the results were not conclusive.

In the current effort, a resistively heated tube experiment was initiated to obtain the detailed data necessary to model the curvature enhancement in high aspect ratio cooling passages. The coolant was gaseous nitrogen. Since the existing gas correlations are well founded for straight smooth-walled tubes, the investigation could be constrained to studying only the test section geometry effects. This report presents the results from tests which include validation of the experimental

"Member AIAA

Copyright $(\odot$ by the American Institute of Aeronautics and Astronautics, Inc. No copyright is asserted in the United States under Title 17, U.S. Code. The U.S. Government has a royaltyfree license to exercise all rights under the copy right claimed herein for Governmental Purposes. All other rights are reserved by the copyright owner. 
facility with a circular test section and limited data from tests using a curved high aspect ratio $(A R=10)$ test section. The results from the circular test section are compared to the existing models for straight, smooth-walled tubes, and the curvature effects observed in the high aspect ratio test section are compared to the curvature factors offered in the literature.

\section{Theory}

The heat transfer coefficient in smooth straight tubes can, in general, be adequately predicted by models in the form of the Colburn equation. 4 Table 1 lists some of the variations that have been developed for straight smooth tubes with coolant properties evaluated at either the bulk or film fluid temperature.4,5 Simoneau and Hendricks ${ }^{6}$ demonstrated that, for a gaseous coolant, the fluid properties could be grouped as a constant, and the heat transfer coefficient modeled by

$$
h=K(\rho V)_{b}^{0.8} d_{h}^{-0.2} \sqrt{T_{b} / T_{w}}
$$

where $K$ is a constant for a given gas, $p$ is density, $\mathrm{V}$ is velocity, $\mathrm{d}_{h}$ is the tube hydraulic diameter, and the subscripts $b$ and $w$ are bulk and wall conditions respectively. To apply any of these equations to a less than ideal situation, such as rocket engine design or analysis, several correction factors are usually applied such that

$$
N u_{\text {calc }}=N u_{s} \cdot \psi_{e} \cdot \psi_{r} \cdot \psi_{c}
$$

where the $\psi$ 's are correction factors and the subscripts $e, r$, and $c$ represent entrance, roughness, and curvature effects. The focus of this paper is $\psi_{c}$, the curvature factor, and the influence of cooling passage aspect ratio on it.

A curvature parameter was developed by Dean 7 for laminar flow which was later successfully applied to predicting frictional pressure loss in a curving tube for laminar flow. Known as the Dean number, De, it is usually written as

$$
D e=\operatorname{Re} \sqrt{\frac{r_{h}}{R_{c}}}
$$

where Re is the Reynold's number and $R_{c}$ is the radius of curvature. Ito ${ }^{8}$ later developed a similar curvature parameter for calculating the friction factor for turbulent flow in curved pipes

$$
\frac{f_{c}}{f_{s}}=\left[\operatorname{Re}\left(\frac{r_{h}}{R_{c}}\right)^{2}\right]^{0.05}
$$

where $f_{c}$ and $f_{s}$ are the curved tube and straight tube friction factors.

Taylor 5 was one of the first to propose applying Ito's 8 curvature factor to the heat transfer coefficient as

$\psi_{c}=\left[\operatorname{Re}_{b}\left(\frac{r_{h}}{R_{c}}\right)^{2}\right]^{ \pm 0.05}$

The positive exponent is applied to the concave side of the tube and the negative exponent is applied to the convex side of the tube.

The experiments of Niino, et al. 9 revealed that although Taylor's factor is applied as a step at the entrance and exit of the curve, the actual curvature enhancement develops through the length of curve and persists beyond the exit of the curve. They obtained a better fit of their data with the following modification to Taylor's factor

$\psi_{c}=\left[\operatorname{Re}_{b}\left(\frac{r_{h}}{R_{c}}\right)^{2}\right]^{ \pm 0.02} \cdot\left[1+b \sin \left(\pi \sqrt{\frac{x_{c}}{L_{c}+15 d_{h}}}\right)\right]$

where $x_{c}$ is the distance from the start of the curve and $L_{c}$ is the length of the curve. Values for the coefficient $b$ of 1 and $1 / 3$ have been used to fit the data from two previous studies.9,10

More recently, Kumakawa et al.11 proposed a slightly different version

$\psi_{c}=\left[\operatorname{Re}_{b}\left(\frac{r_{h}}{R_{c}}\right)^{2}\right]^{ \pm 0.05 \sin \left(\pi \sqrt{\frac{x_{c}}{L_{c}+37 d_{h}}}\right)}$

The modeling capability of these factors will be compared to the experimental results. 


\section{Apparatus and Operating Procedure}

The flow system is shown schematically in figure 1 . A vacuum jacketed run tank is located partially below the floor, and the coolant flows vertically through the system. The tank's vacuum jacket allows for liquid nitrogen to be used as a coolant, but was not necessary for these tests because only gaseous nitrogen was used. The flow rate is redundantly measured by two venturies placed in series in the run tank dip tube, and bulk coolant conditions are obtained in mixing chambers immediately before and after the test section. The test section and mixing chambers are contained in a vacuum chamber to minimize external heat transfer. Heating is accomplished via the resistance of the tube with the electrical power provided by a direct current supply.

Prior to a test, the run tank is charged to the desired pressure. When the test is initiated, the flow rate and back-pressure are controlled to set points by a programmable logic controller operating the respective valves. The power supply is then increased to the desired heat rate and the test section temperatures are allowed to stabilize. Once the temperatures are steady, the data are recorded, usually 10 cycles at 1 second intervals. The power is then cut off, and the tube is allowed to cool before stopping the flow to prepare for the next test condition. Further details of the test rig and operating procedures are described in reference 12 .

\section{Test Hard ware}

Figure 2 is a sketch of test section TS1 and is representative of the instrumentation of test section TS5. Table 2 provides the dimensional details of both test sections. Test section TS1 had a circular cross-section and was considered the checkout tube for validating the rig and data analysis procedures. Copper electrical busses were brazed to the tube for power connection, and extensive thermocouple and pressure tap instrumentation were applied. The thermocouples were spotwelded directly onto the tube, so it was necessary to take care in aligning the junction such that the test section voltage that is picked up by the thermocouple would be minimized. A description of the procedure used to correct this test section voltage induced error is presented in the analysis section.

Test section TS5 had a cross-sectional aspect-ratio of 10 and a $45^{\circ}$ curve in the plane of the larger dimension as depicted in figure 3 . The curve radius to hydraulic radius ratio, $R_{c}$ $/ R_{h}$, was 120 , and the curve began 50 hydraulic diameters downstream of the first copper bus. This insured that the flow was fully developed from both a thermal and velocity standpoint at the entrance of the curve. Test section TS5 was fabricated by machining a curved open channel and electron beam welding the fourth side in place. One advantage of this technique over bending a straight tube is that the wall thickness is known, whereas it is not possible to predict exactly where the wall material will flow during the bending process. The wall thickness is critical in this type of experiment because it determines the local resistance and, hence, heat input to that portion of the tube, and ultimately the surface temperature.

\section{Analysis Procedure}

An analysis was conducted to calculate experimental convective heat transfer coefficients for the test sections from the thermocouple data. The analysis began by correcting the experimentally measured tube surface temperatures for errors due to the test section voltage picked up by the thermocouples. An initial series of tests were conducted at identical flow conditions but reversing the polarity of the voltage applied to the test section. Direct comparison of the temperatures indicated the extent of the error due to misalignment of the junction and the resulting potential picked up. Most of the thermocouples had negligible errors, but several required correction of the measured temperatures. No effort was made to measure the radiative or conductive losses from the thermocouple junctions, but a cursory analysis predicted only negligible losses.

The corrected surface temperatures were then used to calculate inside wall temperatures assuming one dimensional conduction through the thickness of the wall. An iterative procedure that incorporates the variation of the thermal conductivity and electrical resistivity with temperature, similar 
to that employed in reference 13 , was used to obtain both inside wall temperatures and the local heat generation rate. Although the variation in heat generation rate along the length of the tube was determined from the measurements, the heat generation rate was assumed to be uniform through the wall thickness. The bulk temperature of the coolant at each station was calculated from the local heat input and the fluid properties obtained from the subroutine GASP. 14 A heat balance between the electrical power input and the coolant enthalpy gain was calculated as a check, to ensure that the heat losses from the system were not significant. For most of the tests, there was less than $\pm 3 \%$ discrepancy, but a few tests had a difference as large as $\pm 10 \%$. It was believed the larger difference was due to the exit mixer not reaching thermal equilibrium, because of its large thermal mass, and not the result of a heat loss. Once it was determined that the heat balance was acceptable, the local experimental heat transfer coefficient and bulk property experimental Nusselt numbers were calculated.

For test section TS5, the wall temperatures around the perimeter of the test section are not uniform, and the wall thicknesses $(0.127 \mathrm{~cm})$ are equal to the tube width. Therefore, a comprehensive analysis would incorporate three-dimensional conduction in the walls. However, in the present effort, the assumption of onedimensional conduction was maintained. The impact that this assumption will have can be ascertained by considering the temperature gradients between the walls. In the straight thermal entrance region, the shorter walls were considerably hotter (on the order of $100 \mathrm{~K}$ ) than the longer walls. Thus, heat will be conducted away from the shorter walls. However, the one-dimensional analysis assumes this conducted heat is convected to the coolant, and will calculate convective heat transfer coefficients that are slightly high. But, because the focus of this effort is the curvature effect, comparison of the curved section to the straight section should still be valid.

Applying the assumption of onedimensional conduction to the rectangular tube also required special treatment for the heat generated in the corners. This was handled by assuming that the heat generated in each corner was evenly distributed between the adjacent walls, which resulted in higher effective heat generation rates for the shorter walls, because the corner heat was distributed over a smaller area. This is in agreement with the hotter surface temperatures measured on the shorter walls. With these effective heat generation rates, the experimental heat transfer coefficients and bulk property Nusselt numbers could be calculated for each surface of test section TS5.

\section{Results and discussion}

The objectives of these test were to verify the current test and analytical procedures and to compare the predicted heat transfer coefficient curvature enhancement models available in the literature to the experimental enhancement in a high aspect ratio cooling channel. Test section TS1, a circular cross section tube, was used for the former and test section TS5, a curved, rectangular cross-section tube of aspect-ratio 10 , was used for the latter. A D-Optimal experimental test matrix was developed for the controlled experimental conditions: backpressure, flow rate, and applied voltage. This D-Optimal design provides the benefits and efficiency of a designed experiment, but can be applied to an experiment where the design space is constrained. 15 In this case, the highest power input levels could not be operated with the lowest coolant flow rates without overheating the tube walls. The matrix also included several repeated tests. The range of test operating conditions for both test sections is shown in table 3.

A representative wall temperature profile for test section TS1 is plotted in figure 4. While the gradually increasing slope of the wall temperature in the central portion of the tube follows the increase in bulk temperature of the coolant, the drastic effects of the large copper power busses and the flow's thermal development are clear near the ends of the 43 $\mathrm{cm}$ heated section. The heat transfer coefficients are also plotted in figure 4 , and although, as expected, the end effects are strong, the behavior in the central portion of the 
tube is typical of a gas-cooled tube.

The raw data from twenty tests were reduced to obtain experimental Nusselt numbers using bulk fluid properties. The Nusselt numbers were then compared to those predicted by Taylor's model in figure 5 . Although the model included an entrance factor, only the central portion of the tube (from $5 \mathrm{~cm}$ to $35 \mathrm{~cm}$ ) was used for this comparison, to avoid obscuring the results with end effects due to the copper busses. The predicted Nusselt numbers are consistently higher than the experimental values, but fall within $20 \%$.

To improve the fit of the model to the data, a linear regression was performed on the wall-to-bulk temperature ratio exponent, and a value of -0.3 was obtained. The resulting model is compared to the data in figure 6 and shows excellent agreement. Examination of the data presented in reference 6 indicates that an exponent of -0.3 would fit the data better for wall-to-bulk temperature ratios less than two, as in this experiment. The ratio of experimental-to-calculated Nusselt number for the same model is plotted in figure 7 for all of the temperature stations, and shows the good fit in the central portion of the tube but not near the ends.

Typical temperature profiles for the concave and convex walls of test section TS5 are plotted in figure 8 . For a straight tube, one would expect the wall temperature profile to follow the slope of the coolant bulk temperature profile, which is also plotted in figure 8 . However, at the start of the curvature $\left(-\mathrm{X}_{\mathrm{i}}=11\right.$ $\mathrm{cm})$, the concave wall temperature turns dramatically downward. The convex wall profile becomes steeper at this point, but the change is not as dramatic. Unfortunately, the exit of the curve falls within the end effects of the copper power bus and so the wall temperature recovery could not be observed. However, the trends in both profiles are comparable to the curvature effects that have been observed in lower aspect ratio tubes. This indicates that strong secondary flows are present, and the coolant thermal stratification is not significant in the curve for these conditions.

Finding an appropriate model for the curvature effects is more difficult than recognizing their presence. In figure 9 the ratio of experimental Nusselt number to calculated Nusselt number at the concave wall, including Taylor's curvature factor, is plotted for five tests. Because the curvature enhancement increased through the curve, Taylor's factor overcorrected at the entrance to the curve and undercorrected near the exit of the curve. However, the data all falls within \pm $20 \%$.

Figure 10 is a comparison of the experimental curvature factor from a representative test to that predicted by the methods of Taylor 5 , Nino, et al. ${ }^{9}$ and Kumakawa, et al.11 For the Niino et al. equation, the coefficient was assigned the value $1 / 3$. Both the concave and convex surface curvature factors are shown. Note that the predicted values for the two surfaces are not symmetrical because the concave side of the curve is longer than the convex side. Although both the method Taylor and Kumakawa, et al. underpredict the experimentally derived values for the concave surface, Kumakawa's method models the development much better. The method of Niino, et al. over predicted the curvature factor, even though the smaller value of the coefficient $b$ was used. No attempt was made to obtain a better fit of the data, because as noted earlier, the one-dimensional analysis used to determine the experimental Nusselt numbers may have introduced some errors. Therefore, it was not determined whether the discrepancies were real or a result of the simplified analysis. The curvature effect on the convex surface is overpredicted by all three models.

\section{Concluding Remarks}

An electrically heated tube facility was used to investigate the combined effects of cooling channel aspect ratio and curvature. For all of the data presented, gaseous nitrogen was the coolant.

To validate the facility, a single circular cross-section tube was tested, and the results compared favorably with the classical heat transfer correlations available in the literature. 
The results from a curved rectangular cross-section tube of aspect ratio 10 showed that a strong curvature induced heat transfer enhancement was present even at this high aspect ratio. The implication of this result was that secondary flows developed that minimized the coolant thermal stratification. The data also indicated that Taylor's curvature factor, $\psi_{c}$, underpredicted the experimental results by up to $20 \%$. However, the one-dimensional analysis that was applied to the data may have calculated a higher experimental heat transfer coefficient than actually occurred and caused the difference.

The development of an optimum factor for accurately predicting the curvature heat transfer enhancement in high aspect ratio channels will require further testing and more comprehensive analysis of the data, as the results presented here were limited to a single curvature and a single aspect ratio. However, based on these results, the author recommends that, for coolants for which the Colburn type Nusselt number models apply, and up to an aspect ratio of 10, Taylor's factor, or the modified version suggested by Kumakawa, should be used to predict the curvature enhancement in cooling channels.

\section{References}

1. Carlile, J. A., Quentmeyer, R. J., "An Experimental Investigation of High-AspectRatio Cooling Passages," AIAA-92-3154, NASA TM 105679, 1992.

2. Kacynski, K.J., "Thermal Stratification Potential in Rocket Engine Coolant Channels," NASA TM-4378, Presented at the JANNAF Propulsion Meeting, Vol. 1, pp. 329. 338, 1992.

3. Meyer, M. L. and Giuliani, J. E., "Visualization of Secondary Flow Development in High Aspect Ratio Channels with Curvature," AIAA-94-2979, NASA TM106658, 1994.

4. Incropera, F. P. and DeWitt, D. P., Fundamentals of Heat and Mass Transfer, 3rd Edition, John Wiley and Sons, 1990, pp. 495498.
5. Taylor, M. F., "A Method of Predicting Heat Transfer Coefficients in the Cooling Passages of NERVA and PHOEBUS-2 Rocket Nozzles," AIAA-68-608, NASA TM X-52437, 1968.

6. Simoneau, R. J. and Hendricks, R. C., “A Simple Equation for Correlating Turbulent Heat Transfer to a Gas," AIChE and ASME, Heat Transfer Conference and Products Show, Cleveland, Ohio, August 9-12, 1964.

7. Dean, W. R., "Fluid Motion in a Curved Channel," Royal Soc. Proc. A, Vol. 121, 1928, pp. $402-420$.

8. Ito, H., "Friction Factors for Turbulent Flow in Curved Pipes," J. Basic Engineering, Vol. 81, No. 2, June 1959, pp. 123-134.

9. Niino, M., Kumakawa, A., Yatsuyanagi, N., and Suzuki, A., "Heat Transfer Characteristics of Liquid Hydrogen as a Coolant for the LO2/LH2 Rocket Thrust Chamber with Channel Wall Construction," AIAA-82-1107, 1982.

10. Hendricks, R. C., Niino, M., Kumakawa, A., Yeroshenko, V. M., Yaskin, L. A., Majumdar, A. K., and Mukerjee, T., "Friction Factors and Heat Transfer Coefficients for Hydrogen Systems Operating at Supercritical Pressures," Proceedings of Beijing International Symposium on Hydrogen Systems, Beijing, China, May 7-11, 1985, China Academic Publishers, Distributed by Pergamon Press, 1986.

11. Kumakawa, A., Sasaki, M., Niino, M., Sakamoto, H., and Sekita, T., "Thermal Conduction Characteristics of an Electrically Heated Tube Modeled after the LE-7 Main Burner," Presented at the 30th Space Sciences and Technology Conference, October 15, 1986, (paper obtained from the author).

12. Green, J. M., Pease, G. M., and Meyer, M. L., "A Heated Tube Facility for Rocket Coolant Channel Research," AIAA-95-2936, 1995.

13. Hendricks, R. C., Graham, R. W., Hsu, Y. Y., and Friedman, R., "Experimental HeatTransfer Results for Cryogenic Hydrogen Flowing in Tubes at Subcritical and Supercritical Pressures to 800 Pounds Per 
Square Inch," NASA TN D-3095, 1966.

14. Hendricks, R. C., Baron, A. K., and Peller, I. C., "GASP- A Computer Code for Calculating the Thermodynamic and Transport Properties for Ten Fluids: Parahydrogen, Helium, Neon, Methane,
Nitrogen, Carbon Monoxide, Oxygen, Fluorine, Argon, and Carbon Dioxide," NASA TN D-7808, 1975.

15. Federov, V. V., Theory of Optimal Experiments, New York, Academic Press, 1972.

Table 1. Heat Transfer Coefficient Models For Straight, Smooth-Walled Tubes

\begin{tabular}{|l|l|}
\hline Dittus - Boelter 4 & $N u_{s}=0.023 \operatorname{Re}_{b}^{0.8} \operatorname{Pr}_{b}^{0.4}$ \\
\hline Taylor5 & $N u_{s}=0.023 \operatorname{Re}_{b}^{0.8} \operatorname{Pr}_{b}^{0.8}\left(\frac{T_{w}}{T_{b}}\right)^{-\left(0.57-\frac{1.59}{X / D}\right)}$ \\
\hline Sieder-Tate & $N u_{s}=0.027 \operatorname{Re}_{b}^{0.8} \operatorname{Pr}_{b}^{0.8}\left(\frac{\mu_{b}}{\mu_{w}}\right)^{0.14}$ \\
\hline
\end{tabular}

Table 2. Test Section Details

\begin{tabular}{|l|l|l|l|l|l||}
\hline $\begin{array}{l}\text { Test Section } \\
\text { Number }\end{array}$ & Material & $\begin{array}{l}\text { Inside } \\
\text { Dimension }(\mathrm{cm})\end{array}$ & $\begin{array}{l}\text { Outside } \\
\text { Dimension }(\mathrm{cm})\end{array}$ & $\begin{array}{l}\text { Heated } \\
\text { Length }(\mathrm{cm})\end{array}$ & Curvature \\
\hline \hline TS1 & SS 304 & 0.564 diameter & 0.635 diameter & 43.2 & None \\
\hline TS5 & Inconel 718 & $0.127 \times 1.270$ & $0.381 \times 1.537$ & 25.4 & $\begin{array}{l}45^{\circ} \text { Bend with } \\
13.7 \mathrm{~cm} \text { mean } \\
\text { radius }\end{array}$ \\
\hline
\end{tabular}

Table 3. Ranges Of Operating Conditions For Each Test Section

\begin{tabular}{||l|c|c||}
\hline \multicolumn{1}{|c|}{ Parameter } & Test Section TS1 & Test Section TS5 \\
\hline $\begin{array}{l}\text { Bulk Reynolds } \\
\text { Number, Re }\end{array}$ & 400,000 to $1,500,000$ & 250,000 to 900,000 \\
\hline $\begin{array}{l}\text { Wall-to-Bulk } \\
\text { Temperature Ratio, } \\
\mathrm{T}_{\mathrm{w}} / \mathrm{T}_{\mathrm{b}}\end{array}$ & 1 to 2 & 1 to 2 \\
\hline $\begin{array}{l}\text { Back Pressure } \\
\text { (MPa) }\end{array}$ & $2.1,4.8,8.3$ & $2.1,4.5,6.9$ \\
\hline $\begin{array}{l}\text { Coolant Bulk Inlet } \\
\text { Temperature (K) }\end{array}$ & $\sim 280$ & $\sim 280$ \\
\hline $\begin{array}{l}\text { Average Heat Flux, } \\
\text { q ( MW/m } 2)\end{array}$ & $0.30,0.84,1.70$ & $0.34,0.74,1.31$ \\
\hline
\end{tabular}




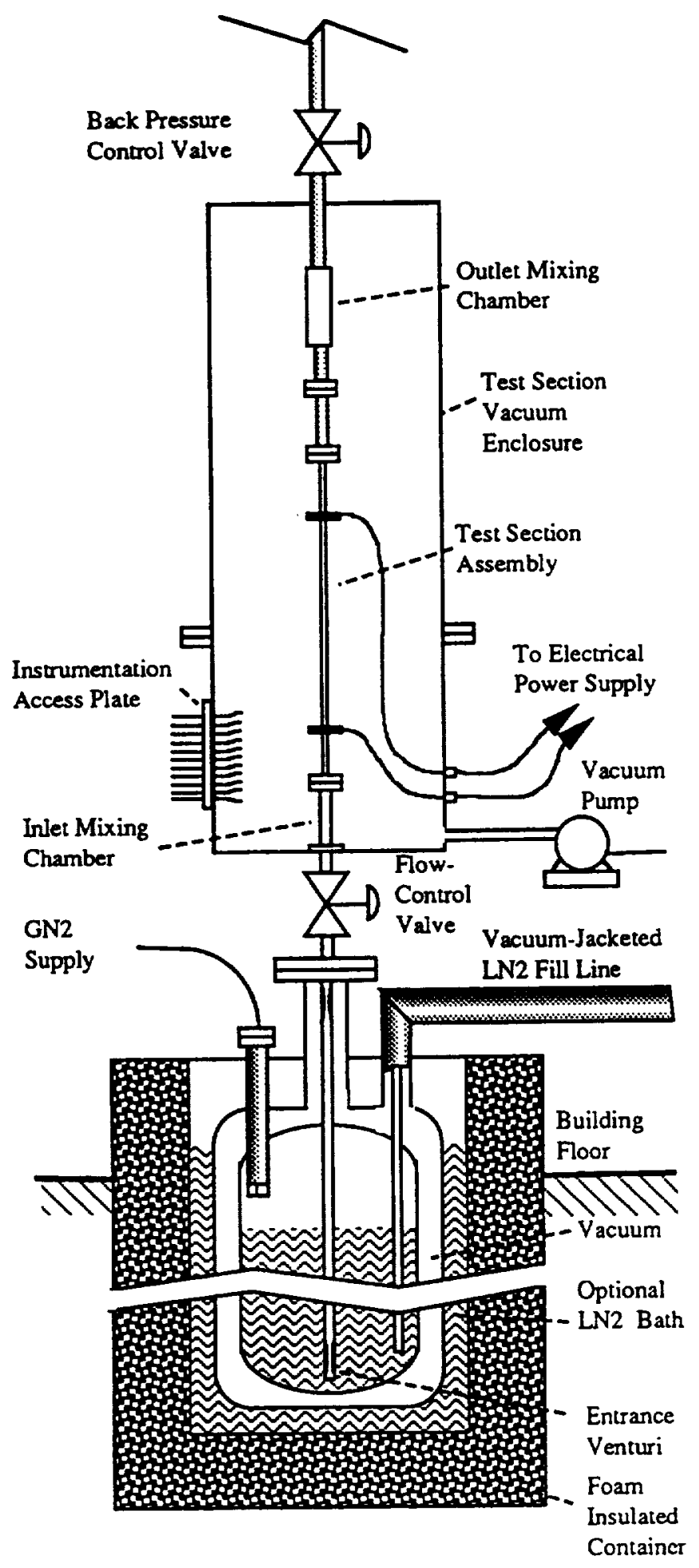

Figure 1. Heated tube facility schematic.

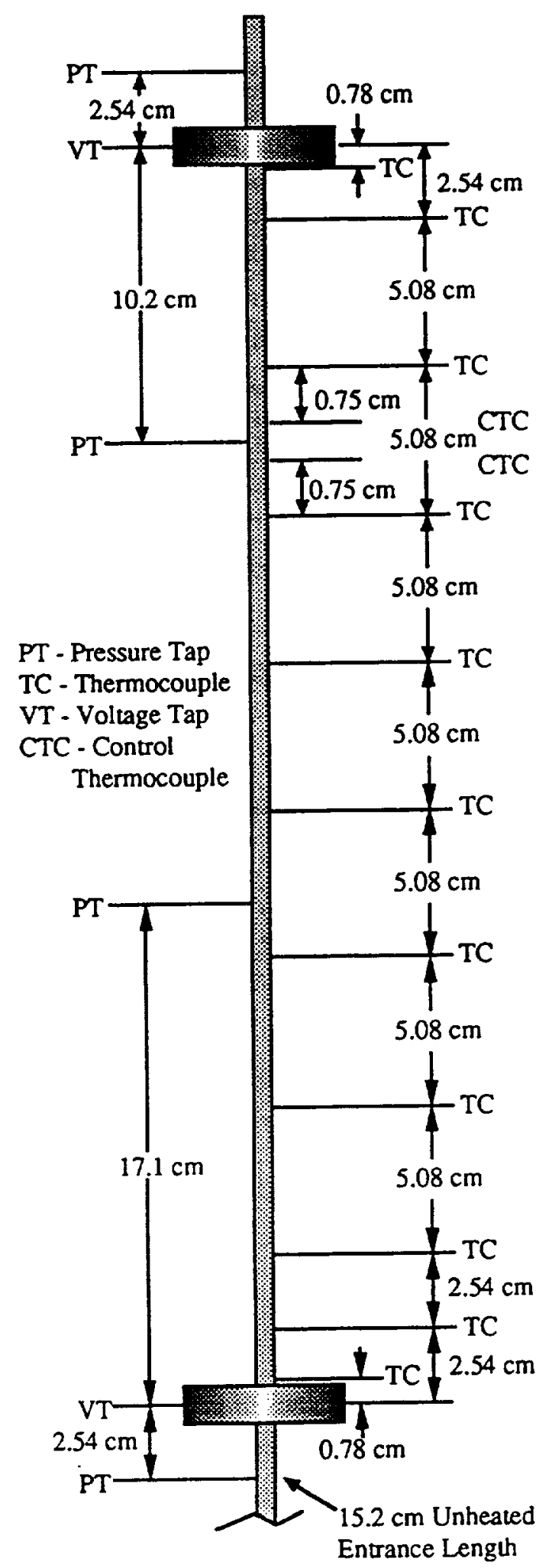

Figure 2. Test section TS1 instrumentation. 


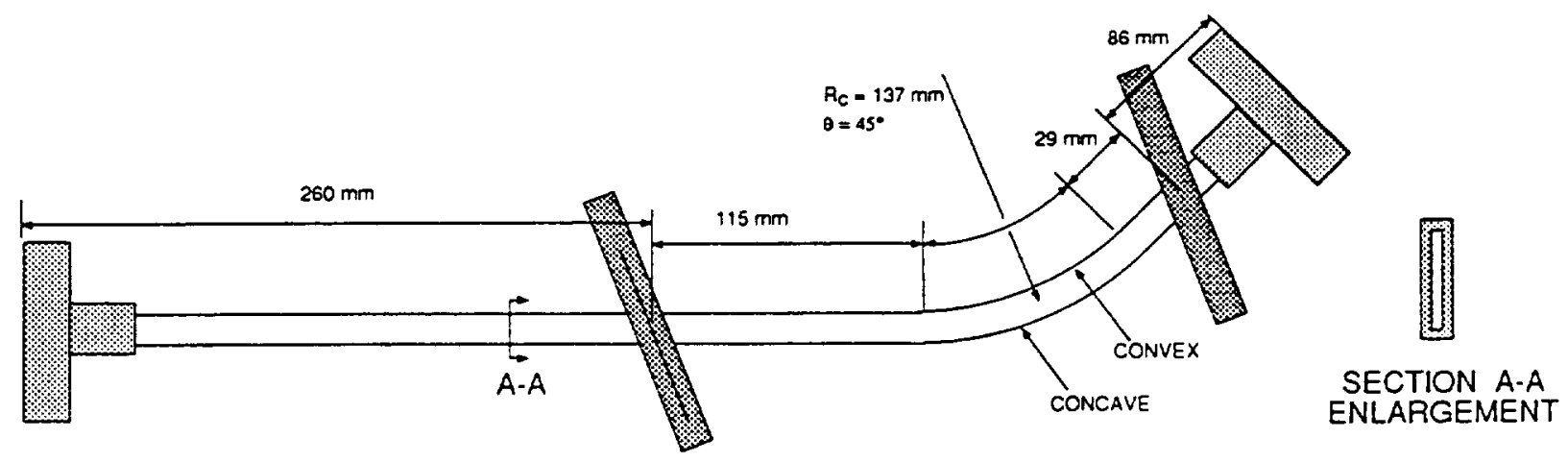

Figure 3. Test section TS5 geometry.

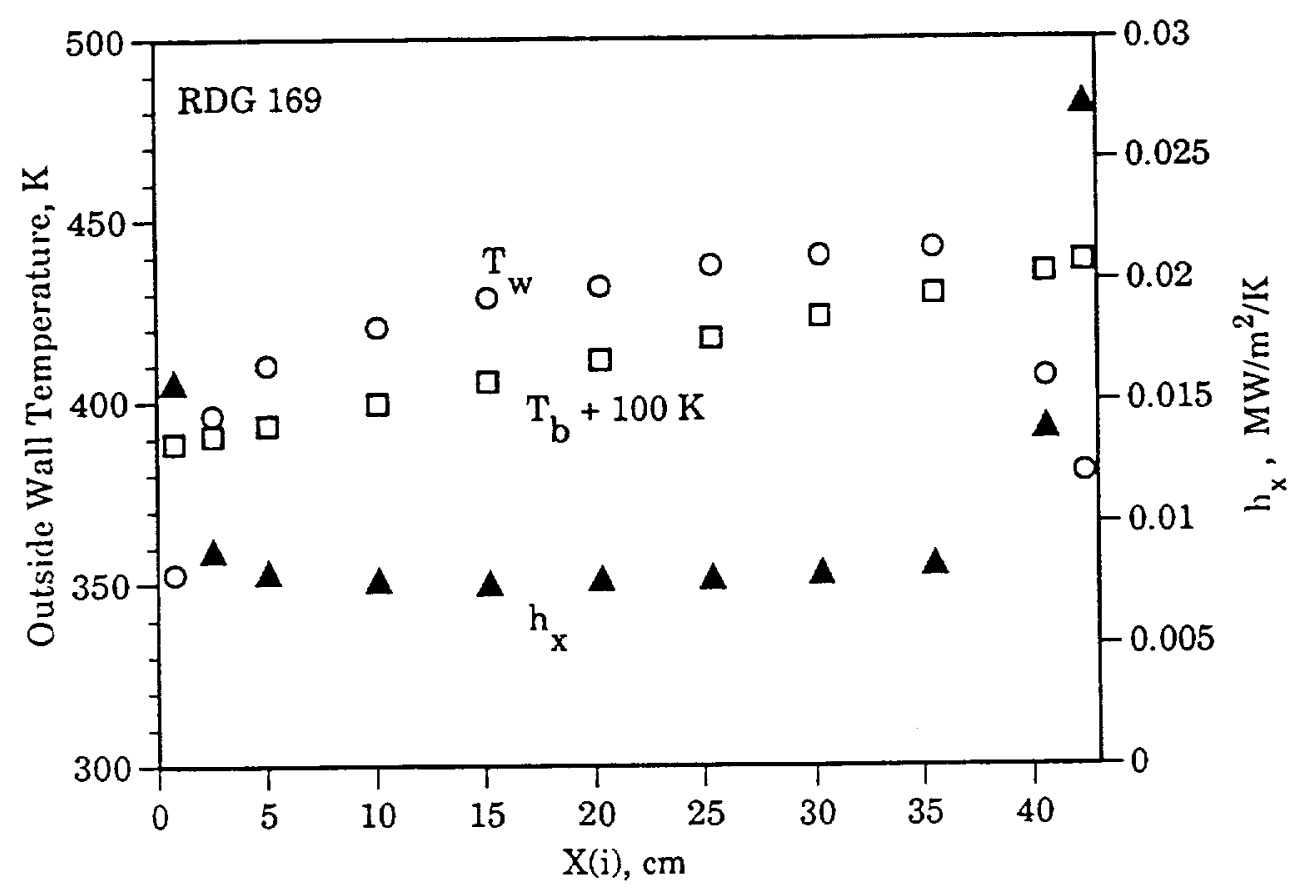

Figure 4. Typical experimental wall temperature $\left(T_{w}\right)$, bulk temperature $\left(T_{b}\right)$, and heat transfer coefficient $\left(h_{x}\right)$ profiles for test section TS1. Bulk temperature is adjusted by a constant $100 \mathrm{~K}$ for the plot. 


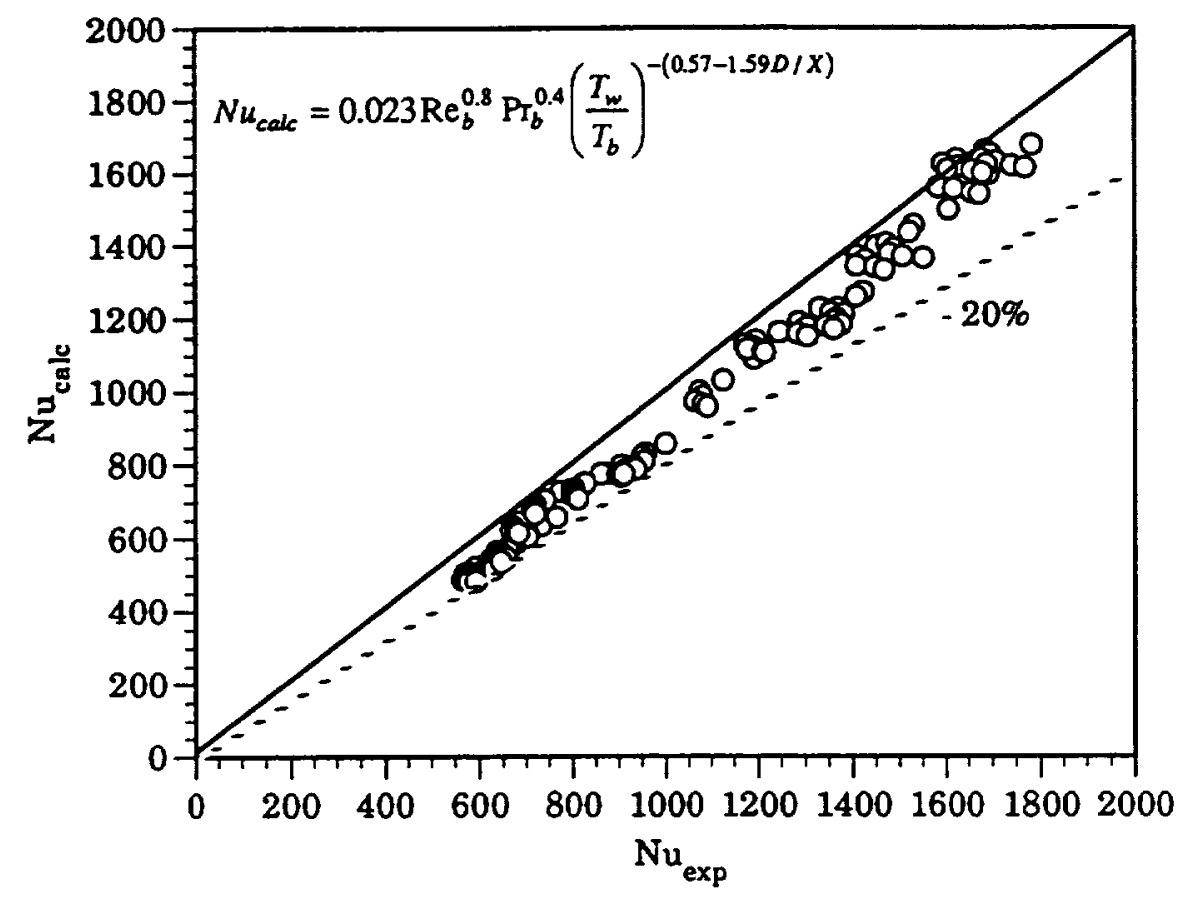

Figure 5. Comparison of Nusselt numbers calculated by Taylor's equation for straight smooth-walled tubes to the experimental values for test section TS1 cooled with gaseous nitrogen.

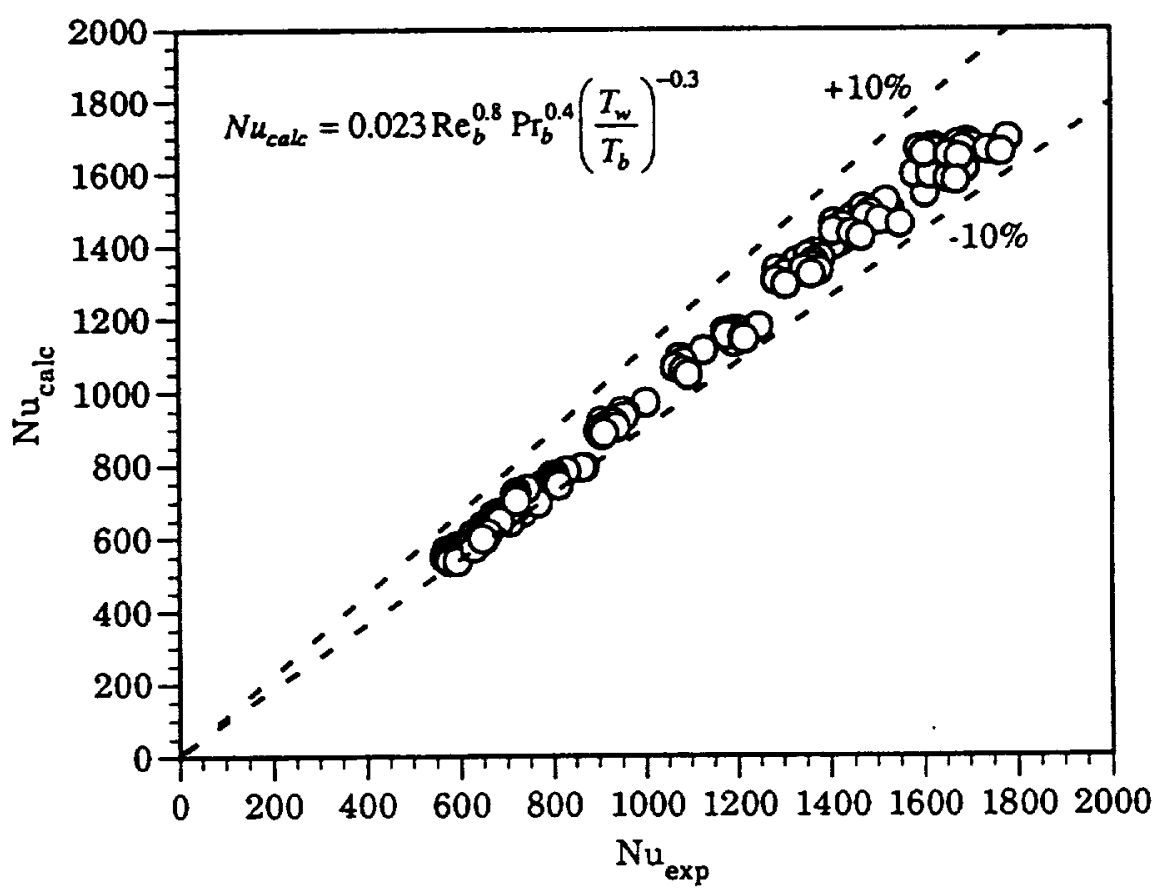

Figure 6. Comparison of Nusselt number calculated with a modified version of Taylor's equation to the experimental values for test section TS1. 


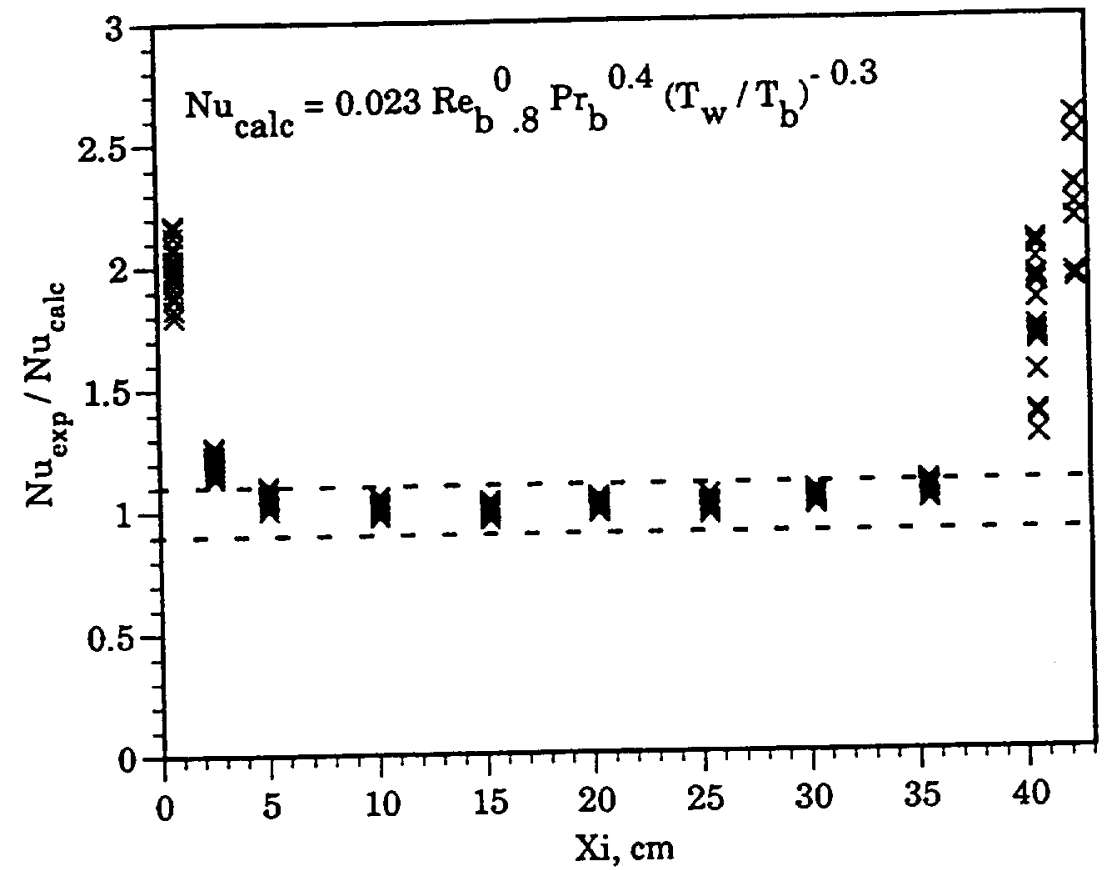

Figure 7. Nusselt number ratios plotted for all temperature stations of test section TS1.

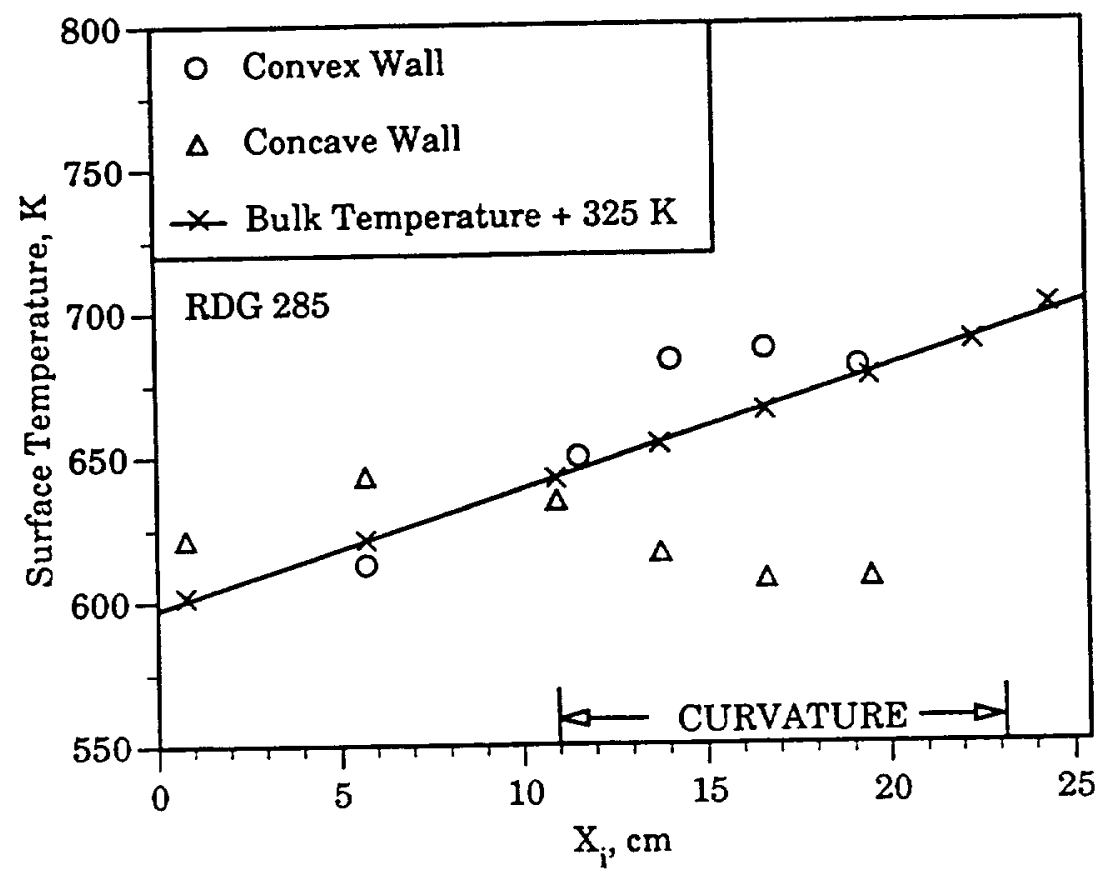

Figure 8. Comparison of typical wall temperature profiles for the concave and convex sides of test section TS5 to the coolant bulk temperature. 


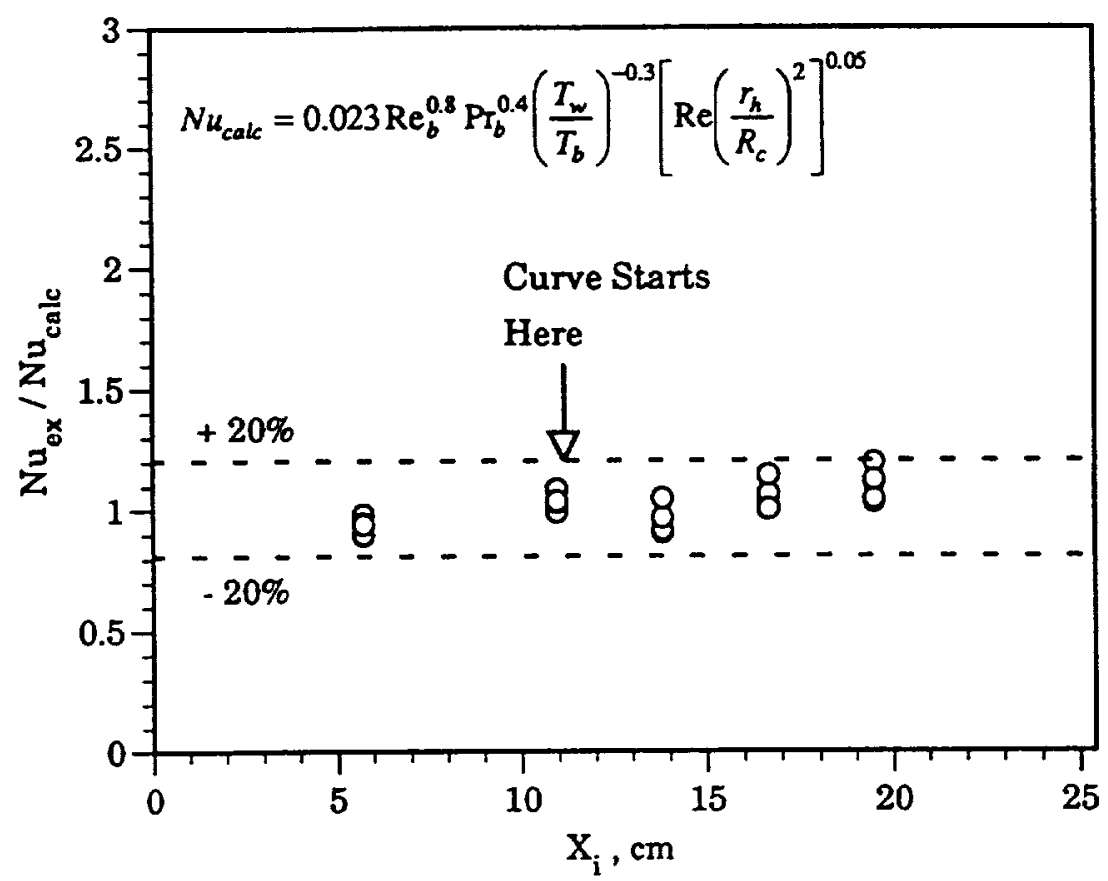

Figure 9. Nusselt ratios for the concave wall of test section TS5 using Taylor's curvature factor.

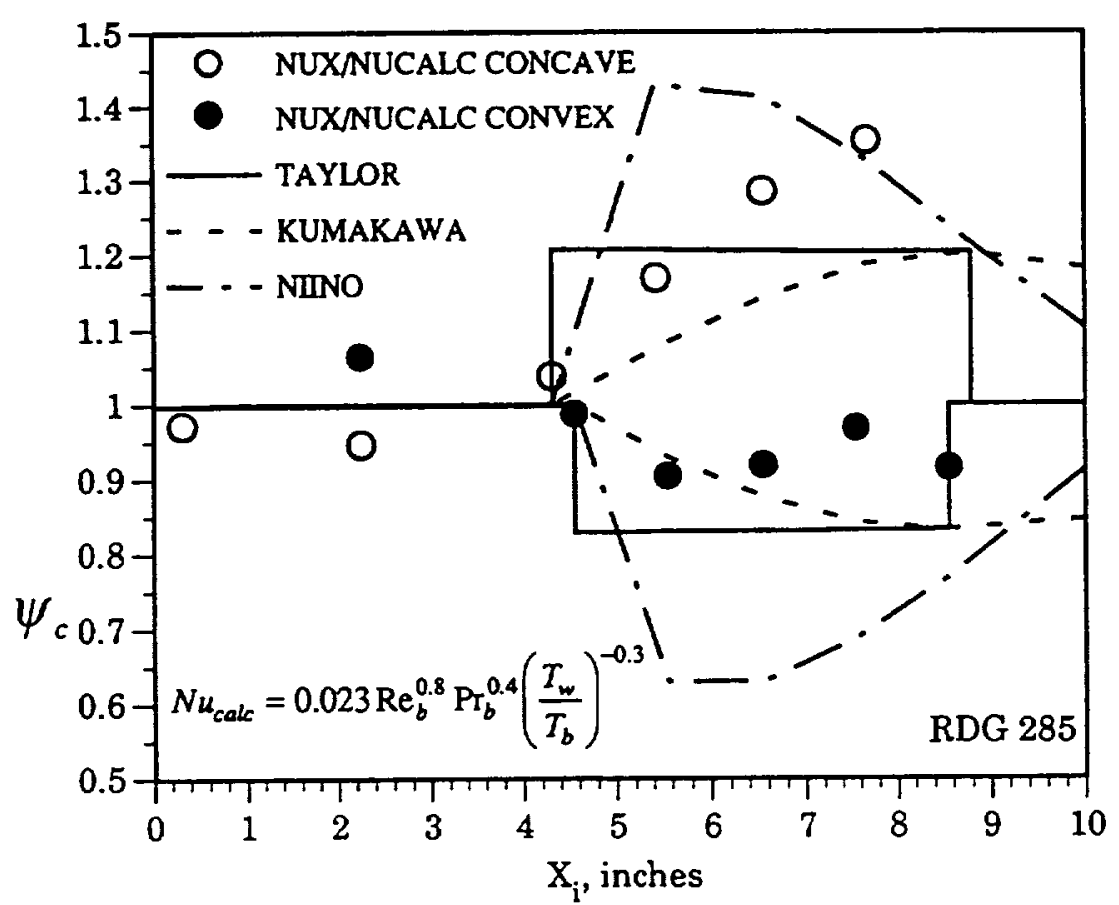

Figure 10. Comparison of curvature factor calculated by the models to typical experimental results. 


\begin{tabular}{|c|c|c|c|c|}
\hline \multicolumn{3}{|c|}{ REPORT DOCUMENTATION PAGE } & \multicolumn{2}{|r|}{$\begin{array}{l}\text { Form Approved } \\
\text { OMB No. 0704-0188 }\end{array}$} \\
\hline \multicolumn{5}{|c|}{ 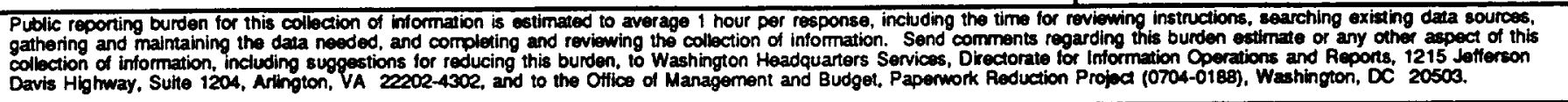 } \\
\hline 1. AGENCY USE ONLY (Leave blank) & $\begin{array}{r}\text { 2. REPORT DATE } \\
\text { June } 1995\end{array}$ & \multicolumn{3}{|c|}{$\begin{array}{l}\text { 3. AEPORT TYPE AND DATES COVEAED } \\
\text { Technical Memorandum }\end{array}$} \\
\hline \multicolumn{3}{|c|}{$\begin{array}{l}\text { 4. TITLE AND SUBTIRE } \\
\text { Electrically Heated Tube Investigation of Cooling Channel Geometry Effects }\end{array}$} & \multicolumn{2}{|c|}{ 5. FUNDING NUMBBERS } \\
\hline \multicolumn{2}{|l|}{ Michael L. Meyer } & 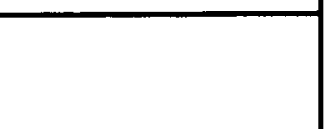 & \multicolumn{2}{|c|}{ WU-242-50-01 } \\
\hline \multicolumn{3}{|c|}{$\begin{array}{l}\text { 7. PERFORLING ORGANIZATION NAME(S) AND ADDRESS(ES) } \\
\text { National Aeronautics and Space Administration } \\
\text { Lewis Research Center } \\
\text { Cleveland, Ohio } 44135-3191\end{array}$} & \multicolumn{2}{|c|}{$\begin{array}{l}\text { 8. PERFORMANG ORGANIZATION } \\
\text { REPORT NUMBER } \\
\text { E-9760 }\end{array}$} \\
\hline \multicolumn{3}{|c|}{ 9. SPONSORINGMONITOPANG AGENCY NAME(S) AND ADDRESS(ES) } & 10. SP & $\begin{array}{l}\text { NSORINGANONTORING } \\
\text { NCY REPOAT NUMBER } \\
\text { AA TM-106985 } \\
\text { A-95-2500 }\end{array}$ \\
\hline \multicolumn{5}{|c|}{$\begin{array}{l}\text { Prepared for the 31st Joint Propulsion Conference and Exhibit cosponsored by AIAA, ASME, SAE, and ASEE, San } \\
\text { Diego, California, July 10-12, 1995. Responsible person, Michael L. Meyer, organization code 5310, (216) 977-7492. }\end{array}$} \\
\hline \multicolumn{3}{|c|}{$\begin{array}{l}\text { 12a. DISTRIBUTIONAVAILABILTY STATEMENT } \\
\text { Unclassified - Unlimited } \\
\text { Subject Category } 20 \\
\text { This publication is available from the NASA Center for Aerospace Information, (301) 621-0390. }\end{array}$} & \multicolumn{2}{|c|}{ 12b. DISTRABUTION CODE } \\
\hline \multicolumn{5}{|c|}{$\begin{array}{l}\text { The results of an experimental investigation on the combined effects of cooling channel aspect ratio and curvature for } \\
\text { rocket engines are presented. Symmetrically heated tubes with average heat fluxes up to } 1.7 \mathrm{MW} / \mathrm{m}^{2} \text { were used. The } \\
\text { coolant was gaseous nitrogen at an inlet temperature of } 280 \mathrm{~K}\left(500^{\circ} \mathrm{R}\right) \text { and inlet pressures up to } 1.0 \times 10^{7} \mathrm{~N} / \mathrm{m}^{2}(1500 \\
\text { psia). Two different tube geometries were tested: a straight, circular cross-section tube, and an aspect-ratio } 10 \mathrm{cross}- \\
\text { section tube with a } 45^{\circ} \text { bend. The circular tube results are compared to classical models from the literature as validation of } \\
\text { the system. The curvature effect data from the curved aspect-ratio } 10 \text { tube compare favorably to the empirical equations } \\
\text { available in the literature for low aspect ratio tubes. This latter results suggests that thermal stratification of the coolant } \\
\text { due to diminished curvature effect mixing may not be an issue for high aspect-ratio cooling channels. }\end{array}$} \\
\hline \multirow{2}{*}{\multicolumn{3}{|c|}{$\begin{array}{l}\text { 14. SUBJECT TERMS } \\
\text { Heat transfer; Heat transfer coefficients; Curvature; High aspect ratio; } \\
\text { Rocket engine design; Cooling; Tubes; Resistance heating }\end{array}$}} & & $\begin{array}{l}\text { 15. NUMBER OF PAGES } \\
14\end{array}$ \\
\hline & & & & $\begin{array}{r}\text { 16. PRICE CODE } \\
\text { A03 }\end{array}$ \\
\hline $\begin{array}{l}\text { 17. SECURTY CLASSIFICATION } \\
\text { OF REPORT } \\
\text { Unclassified }\end{array}$ & $\begin{array}{l}\text { 18. SECURITY CLASSIFICATION } \\
\text { OF THIS PAGE } \\
\text { Unclassified }\end{array}$ & $\begin{array}{l}\text { 19. SECURITY CLASSIFICA } \\
\text { OF ABSTRACT } \\
\text { Unclassified }\end{array}$ & & 20. LIMTTATION OF ABSTRACT \\
\hline
\end{tabular}


